Lunar Halos: their Origin and Prognostic Significance

M. W. DE FONvielLe is, no doubt, right in attaching importance to the study of these phenomena of refraction, depending as they do, upon the polarisation of atmospheric vapour. Rightly interpreted, they afford one of the most certain indications of weather change, especially in regard to rain; but the popular notion of their being precursors of storms is certainly exaggerated. In reply to hee inquiry made by $M$. de Fonvielle, I may say that the distance between the observers of the singular forms of this phenomenon, and seen on January 4 th (and of which a sketch, furnished by me, was inverted by the printer) was about two statute miles. I have ascertained that the two arcs in my own sketch corresponded with the largest and the smallest circles in the drawing of your other correspondent. I saw nothing of the intermediate intersecting arc, almost vertical ${ }^{*}$ in his drawing.

$M$. de Fonvielle does not, however, remark on the fact that the great circle of $90^{\circ}$ had the moon in its circamference. Allow me also to add that in my own sketch the apparent diameter of the moon and of the imperfect paraselene are exaggerated; the object of the drawing being to show the relative magnitude and position of the two circles. The innermost circle in both drawn ings was about $45^{\circ}$ to $50^{\circ}$-in fact an ordinary lunar halo. All my observations (for many years) have pointed to the inference, which I may call a law, "That halos indicate a change of temperature, and are indicative of transition from ary to wet as well as from wet to dry." I shall be happy to forward M. de Fonvielle further information if desired.

Aigburth, Liverpool, March 20

SAMUel Barber

\section{Science in Schools}

IN the last number of your paper a correspondent, "W.," asks for information respecting "any school adapted for young boys whose parents wish to give them an education embracing the physical sciences and modern languages, on some such plan as that of the Realschule of Germany." Will you permit me to state that the International College at Spring Grove was established with precisely this object, and to a prospectus of this college, which I send you, I would direct the attention of your correspondent. The scheme of science instruction for this college was drawn up by Professors Huxley, Tyndall, and Williamson, and for upwards of four years past has been carried into operation as closely as circumstances permit.

Isleworth

W. F. B.

IN reply to "W." will you allow me to forward you a prospectus of Craufurd College, Maidenhead, in which an education is given embracing the physical sciences and the modern languages. Having many years ago visited the Realschule of Offenbach, and attended the classes of several of the professors in that school, I have no hesitation in expressing my opinion that a comparison of the merits of the two schools would not be unfavourable to the former.

ANGLICUS

\section{Morell's Geometry}

As a considerable part of your number of February 23 is devoted to comments on a little pulblication just issued by me, "The Essentials of Geometry," I must request you in courtesy to insert lhese lines in order to set right one misconception. "The Reviewer" (p. 323) passes certain criticisms on the definitions and enunciations, as well as demonstrations, of the book, describing the former as having salient incongruities, and the latter as being nonsense. These are strong expressions, but my present purpose is not to expose the fallacy of the remarks in the review, but to point out the fact noticed in the preface, and overlooked by the reviewer, that all the proofs in the work are taken from French and German sources (p. viii.)

I may add that those sources are the most approved in neighbouring countries, and though I have not given my references in every case, $I$ have done so in so many cases that any person of ordinary discrimination might have inferred that every statement and proof advanced had some high authority for warrant. It is to be regretted that the "Reviewer" overlooked this, for in his haste to condemn a method for which he has an antipathy, he has been betrayed into accusing some even of the leading Iritish as well as foreign geometricians as guilty of salient incongruities, and of writing nonsense. Thus the definition of a plane angle, though condemned by "'The Reviewer," is almost identical with that of Dr. Thomson in his edition of Euclid (1835), Def. 7 , and the Note to it which runs: "A rectilinear angle is the degree of opening or divergence of two straight lines which meet one another." Nor does Euclid's original definition of an angle differ

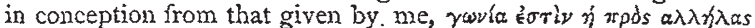
$\tau \hat{\omega} \nu$ ypa, $u \mu \hat{\omega} \nu \kappa \lambda i \sigma t s$; for this word $\kappa \lambda i \nu \in i \nu$ contains the notion of revolution, that is, of more or less. Compare my second des. nition of an angle. - Essentials, No. 68, p. 40.

Again, the enunciation and demonstration of the two funclamental theorems of parallels are qualified as sheer nonsense, and yet the whole passage is textually the same as Amiot's, including the parts printed in italics. Further, the preof of the equality of triangles at p. 44 , condemned as a violation of the common rules of logic, is based on the previous pages 42,43 , overlooked by "The Reviewer," and agrees almost word for word with Legendre, and absolutely with M. Bos, Professor of the Lycce St. Louis at Paris, and successor of Amiot. (See his "Nlemento du Baccalaureat es Lettres," 1866-68, p. 183. Partie Scientifique.)

It would take up too much time and space to go further into the matter in dispute, but I wish it to be clearly understood, without denying the right of "The Reviewer" to attack the book in any way that is fair and reasonable, that it is neither one nor the other to make Mr. Morell the object of all the attacks when he is far too honoured in being treated as the substitute for many of the first geometers of the present age on whom the punishment descends.

Every statement and proof in the work has for its warrant some high authority, and the basis of the work and most parts of it to which no special references are given in foot-notes are taken from a digest published by University examiners and Doctors of Science on the Continent.

Now, Sir, as the present letter does not presume to enter on a discussion of the merits or demerits of the work, but is simply an explanation of an essential point underlying the whole question and overlooked by "The Reviewer," I must, as I have said before, request these remarks to be inserted in NATURE to set right the mistake about the authorship and authority of the book.

If NATURE will have the courtesy to give me a little more space on a future occasion, I hope to show on my own authority that I have good arguments for what has been advanced.

March 15

J. R. MORELL

\section{Work and Force}

As I hope to hear more of Mr. Highton's arguments at the meeting of the Literary and Philosophical Society of Manchester before this is printed, I will content myself now with noticing but two points.

The first is his attempt to deferid himself from the charge of confusing Work and Force; there are other passages in his writings which lead to this somewhat serious conclusion; but the vagueness of the expression "the total of the force used" would suffice to make anyone suspect some such confusion. I presume that a "total of force" is still force, and can therefore be no more equivalent to work than to a time or a space.

The other point is the sentence "this only shows that one of the laws of thermo-dynamics is inconsistent with the doctrine of the mechanical equivalence of heat." If Mr. Highton knew that the first law of thermo-dynamics simply asserted this equivalence he would surely have expressed the proposition differently. As it stands in form it is very much t:e same as it he had said that one of Newton's laws of moiion was inconsistent with the principle that a particle acted on by no forces will move uniformly in a straight line.

If he had known what the laws were, he would hardly have said that they were inconsistent with the very principle which the first asserts, and which the second, as usually stated, involves. of course, these lines are not meant as an answer to $\mathrm{Mr}$. Highton's letter, but merely to show that he really does not quite understand the theory he criticises. March 18

\section{J. HOPKINSON}

INVINCIBLE ignorance is said to be excusable. This must be my plea, when I say that I have read over again Sir W. Thomson's paper in the "Philosophical Magazine" of Feb. 1854, and that I camnot see but that it leads to perpetual motion more than anything I have ever written.

H. HIGHTON 